\title{
Hepatitis C virus management: potential impact of nanotechnology
}

\author{
Mostafa H. Elberry ${ }^{1,2}$, Noureldien H. E. Darwish ${ }^{1,3}$ and Shaker A. Mousa ${ }^{1 *}$
}

\begin{abstract}
Around 170-200 million individuals have hepatitis C virus (HCV), which represents $\sim 3 \%$ of the world population, including $\sim 3-5$ million people in the USA. According to the WHO regional office in the Middle East, Egypt has the highest prevalence in the world, with 7\% prevalence in adults. There had been no effective vaccine for HCV; a combination of PEG-Interferon and ribavirin for at least 48 weeks was the standard therapy, but it failed in more than $40 \%$ of the patients and has a high cost and serious side effects. The recent introduction of direct-acting antivirals (DAA) resulted in major advances toward the cure of HCV. However, relapse and reduced antiviral efficacy in fibrotic, cirrhotic HCV patients in addition to some undesired effects restrain the full potential of these combinations. There is a need for new approaches for the combinations of different DAA and their targeted delivery using novel nanotechnology approaches. In this review, the role of nanoparticles as a carrier for HCV vaccines, anti-HCV combinations, and their targeted delivery are discussed.
\end{abstract}

Keywords: Hepatitis C virus, Drug delivery system, HCV genotypes, Nanoparticles

\section{Background}

From the time of its discovery in 1989, hepatitis $C$ virus $(\mathrm{HCV})$ has been known globally as the primary reason for chronic liver disease [1]. HCV persistent infection is accompanied by liver cirrhosis, hepatocellular carcinoma, end stage liver disease and finally death [2]. Up to $3 \%$ of the world's population, about 200 million individuals, is estimated to have HCV infection [3].

Among all the people infected with $\mathrm{HCV}$, there are at least six genotypes [4] as a result of the high error rate of RNA-dependent RNA polymerases during HCV replication [5]. Genotype 1 (G1) is the most predominant in the world ( $~ 83.4$ million people) followed by G3 ( $\sim 54.3$ million), then G2, G4 and G6 ( 15.6 million), and G5 ( 1.4 million) [6]. HCV transmission mainly occurs through contaminated blood and blood products transfusion, injection drug use, hemodialysis and organ transplantation; however unprotected sexual intercourse and birth from an infected mother have also been documented as other modes of transmission [7, 8].

\footnotetext{
* Correspondence: shaker.mousa@acphs.edu

${ }^{1}$ The Pharmaceutical Research Institute, Albany College of Pharmacy and Health Sciences, Rensselaer, NY 12144, USA

Full list of author information is available at the end of the article
}

Until 2011, the standard treatment was a blend of subcutaneous pegylated interferon (PEG-IFN) in addition to oral ribavirin (RBV), administered for 24 or 48 weeks [9]. The cure rate depends on the viral genotypes. IFN-alpha and RBV failed to eliminate $\mathrm{HCV}$ in $50-60 \%$ of patients infected with G1 and G4 and about $20 \%$ of patients with G2 and G3 [10]. Development of a new, specifically targeted antiviral therapy for $\mathrm{HCV}$ was a must to overcome the shortcomings of PEG-IFN/RBV therapy. This new targeted HCV therapy, called directacting antivirals (DAA), has been used in combination with PEG-IFN/RBV as a triple therapy since 2011. The first generation of protease inhibitors (PIs) DAA, telaprevir and boceprevir, was used in addition to PEG-IFN/ RBV in the treatment of G1. They were associated with increased sustained virological response (SVR) rates up to $75 \%$ and $79 \%$, respectively. Unfortunately they increased adverse effects and led to $\mathrm{HCV}$ drug-resistant mutants to both PIs [11-13]. Because of these drawbacks, a second wave of PIs is being developed, such as simeprevir and the second generation PI grazoprevir, in addition to nucleoside/nucleotide analogues like sofosbuvir and nonstructural protien 5A (NS5A) such as daclatasvir DAAs. These more efficient regimes are well-tolerated, pan-genotypic, and have a low tendency 
to develop viral resistance [14]. Along with DAAs, a number of host targeting antivirals (HTAs) have been developed. They act on host key enzymes or some cellular factors essential for the HCV life cycle [15]. The advantage of HTAs is that they have an extremely low rate of mutation in the host cell. The main targets of HTAs are cyclophilin A (CypA), miRNA, and fatty acid synthase.

The field of nanotechnology provides manipulation at the molecular level, and in the pharmaceutical field, nanomaterials have had a great impact on the enhancement of drug properties. Nanomaterials used in formulations can add high value due to their high dissolution rates, which can improve a drug's bioavailability and stability. Biodegradable and biocompatible nanoparticles can be used as carriers for synthetic proteins, lipids, polysaccharides, and biopolymers [16]. Nanomaterials can also target specific organs, tissues, or even cells [17]. The introduction of anti-HCV targeted delivery using nanovectors, which carry the drug to its site of action, helps minimize the side effects of non-specific targeting and enhances therapeutic efficacy [18]. The aim of this review is to summarize new regimens for HCV treatment and the possible role of nanotechnology as a targeted delivery system that increases bioavailability and sustained drug release while decreasing severe side effects during $\mathrm{HCV}$ treatment. Techniques using nanoparticles to improve anti-HCV agents are listed in Table 1, and a summary diagram of nanoparticles used as carriers for anti-HCV agents is in Fig. 1.

\section{HCV virology}

$\mathrm{HCV}$, one of the Flaviviridae virus family, is an enveloped positive single-stranded RNA virus. The $\mathrm{HCV}$ genome has 9600 bases, forming a continuous open reading frame edged by 5' and 3' non-translated regions [19]. The 5' non-translated region contains an internal ribosome entry site (IRES) that is essential to initiate the translation of the HCV genome [20]. The IRES-mediated translation produces an approximately 3000 amino acid polyprotein precursor. It subsequently cleaves co- and post-translationally into mature viral structural and nonstructural (NS) proteins. The proteolytic processing of of the polyprotein is done by cellular peptidases [21] and two viral proteases, NS2/3 and NS3 [22, 23], which breaks it into 10 functional subunits: structural Core (C), envelope (E1 and E2) proteins, ion channel p7, and NS proteins NS2, NS3, NS4A, NS4B, NS5A and NS5B [24]. Subunits C, E1, and E2 form the virus particles in which nucleocapsid is constructed from repeated copies of the core protein, while E1 and E2 form the envelope glycoproteins. P7 may have a function in assembly and release of the viral particles. The NS proteins from NS3 to NS5B form the viral replicase complex. Also, NS5B forms the RNA-dependent RNA polymerase [25] (Fig. 2).

\section{New treatments for HCV}

There are many FDA-approved anti-HCV therapies (Table 2), and some are still in different clinical trial phases.

\section{Genotype 1}

A recent phase II, open-label study assessed the use of daclatasvir $(30 \mathrm{mg}$ ) plus simeprevir $(150 \mathrm{mg})$ with or without RBV in G1 (a and b subtypes). For G1b treatment-naïve patients cirrhotic or non-cirrhotic, sustained virological response for 12 consecutive weeks (SVR12 rate) was $84.9 \%(45 / 53)$ and $74.5 \%(38 / 51)$ with and without RBV, respectively. For prior null responders it was $69.6 \%(16 / 23)$ and $95.0 \%(19 / 20)$ with and without RBV, respectively. In patients who completed 24 weeks, treatment duration had no significant impact on response; on the other hand, for G1a, the two DAAs with RBV provided a sustained virological response for 24 consecutive weeks (SVR24 rate) of $66.7 \%$ (8/12) in treatment-naïve patients, but they were not effective in prior null responders [26].

An open-label, phase II safety study of telaprevir and sofosbuvir in chronic hepatitis C G1 was conducted for 12 weeks on 20 non-cirrhotic and naïve HCV G1 infected patients who received telaprevir $(1125 \mathrm{mg})$ twice per day and sofosbuvir (400 mg) once daily. The SVR12 rate after the end of treatment was $95 \%$. The treatment was associated with some undesirable side effects such as a headache, pruritus, rash, and anorectal symptoms [27].

The OPTIMIST-1 open-label, phase III study of HCV G1 patients tested the efficacy and safety of simeprevir $(150 \mathrm{mg})$ plus sofosbuvir $(400 \mathrm{mg})$ for 8 or 12 weeks in both previously untreated and treatment-experienced non-cirrhotic patients. Results were an SVR rate of $83 \%$ in the 8-week treatment group, which was significantly lower than the SVR12 rate (97\%) in the 12-week group. The study showed that the 8-week arm had high SVR12 rates only in subgroup $1 \mathrm{~b}$ patients [28].

\section{Genotype 2}

In a recent open-label, phase II study performed by a New Zealand team on 53 patients with HCV G2 (23\% treatment-experienced and $4 \%$ with cirrhosis), sofosbuvir plus ledipasvir was administered for 8 or 12 weeks and achieved SVR rates of $74 \%$ and $96 \%$, respectively. The most common side effects were headache, nausea, fatigue and upper respiratory tract infection $[29,30]$.

\section{Genotype 3}

The ALLY3 phase III clinical trial studied the effectiveness of 12 weeks' combined therapy of sofosbuvir $(400 \mathrm{mg})$ and daclatasvir (60 mg) in 152 G3 infected patients. For both naïve $(n=101)$ and treatment-experienced $(n=51)$ patients, SVR12 rate was 90\% (91/101) and 86\% (44/51), respectively. It was distinctly lower in patients with 
Table 1 Advantages of using nanoparticles as a carrier for some anti-HCV compounds

\begin{tabular}{|c|c|c|}
\hline Carrier for: & Composition & Advantages \\
\hline RBV-boronic acid & $\begin{array}{l}\text { PGA and acylated PGA NPs encapsulating } \\
\text { RBV-boronic acid }\end{array}$ & $\begin{array}{l}\text { Decreases RBV accumulation in red blood } \\
\text { cells to help prevent hemolytic anemia }\end{array}$ \\
\hline RBV monophosphate & $\begin{array}{l}\text { Mixture of arabinogalactan-poly } \\
\text { (L-lysine) and poly ( } \mathrm{D}, \mathrm{L} \text {-lactic acid) polymer }\end{array}$ & $\begin{array}{l}\text { 1- Stable, biodegradable nanocomplex } \\
\text { 2- Dual function of targeting hepatocytes } \\
\text { and sustained release of RBV } \\
\text { 3- RBV accumulates in liver of mice after i.v. } \\
\text { administration of RBV monophosphate, then } \\
\text { RBV content gradually decreases for at } \\
\text { least } 7 \text { days }\end{array}$ \\
\hline CsA & PLGA NPS & $\begin{array}{l}\text { 1- Reduces toxic effects associated with } \\
\text { free CsA } \\
\text { 2- Decreased immunosuppressive effects } \\
\text { compared to conventional treatment } \\
\text { with CsA }\end{array}$ \\
\hline HCV vaccine & $\begin{array}{l}\text { CpG oligodeoxynucleotide + recombinant HCV } \\
\text { NS3 encapsulated in a cationic liposome }\end{array}$ & $\begin{array}{l}\text { Increases not only cellular but also humoral } \\
\text { immune response against HCV NS3 }\end{array}$ \\
\hline Anti-HCV peptides & $\begin{array}{l}\text { P41, peptide derived from HCV NS5A + ionic } \\
\text { nanocomplex }\end{array}$ & $\begin{array}{l}\text { 1- Decreases cytotoxicity, hemolytic effect } \\
\text { and proteolytic degradation while maintaining } \\
\text { antiviral activity against HCV } \\
\text { 2- Inhibits HCV core and NS5A proteins from } \\
\text { binding with lipid droplets, which is known to } \\
\text { be an essential step for viral assembly and release }\end{array}$ \\
\hline Anti-HCV siRNA & $\begin{array}{l}\text { Galactose functionalized dendritic } \\
\text { nanovector + siRNA against the } 5^{\prime} \text { untranslated } \\
\text { region of HCV genome }\end{array}$ & $\begin{array}{l}\text { 1- Improves cellular uptake of siRNA } \\
\text { 2- Decreases rapid degradation of siRNA by } \\
\text { nucleases and improves their blood stability }\end{array}$ \\
\hline Anti-HCV deoxyribozymes & $\begin{array}{l}\text { Iron oxide magnetic NPs as a carrier for } \\
\text { DNAzyme Dz681 }\end{array}$ & $\begin{array}{l}\text { 1- Inhibits HCV NS3 replication through the } \\
\text { knockdown of HCV NS3 gene expression } \\
\text { 2- Higher knockdown efficiency than free } \\
\text { DNAzyme transfected with Lipofectamine } 2000 \\
\text { 3- Did not induce any undesired immune } \\
\text { responses in vitro }\end{array}$ \\
\hline Anti-HCV phenolic compounds & $\begin{array}{l}\text { Silibinin, the active polyphenolic agent of } \\
\text { milk thistle, incorporated with liposomes } \\
\text { as a nanovector }\end{array}$ & $\begin{array}{l}1 \text {-Improves solubility and delivery of silibinin } \\
2 \text {-Non-toxic and high antiviral activity to } \\
\text { prevent entry with preferential absorption } \\
\text { by hepatocyte }\end{array}$ \\
\hline Anti-HCV aptamer & $\begin{array}{l}\text { Magnetic nanoconjugate + aptamer } \\
\text { (Apt-E1E2-6) }\end{array}$ & $\begin{array}{l}\text { 1- Efficiently eradicates HCV particles and decreases } \\
\text { the viral titer from human plasma samples } \\
\text { 2- Provides non-invasive technique for HCV } \\
\text { removal with minimal side effects }\end{array}$ \\
\hline $\begin{array}{l}\text { HCV polymerase inhibitors and } \\
\text { protease inhibitors }\end{array}$ & $\begin{array}{l}\text { HCV protease and polymerase } \\
\text { inhibitors + anti-fibrotic/anti-hemolytic + viral } \\
\text { entry inhibitor agents + naturally driven } \\
\text { polyphenol/thiols and non-anticoagulant GAGs }\end{array}$ & $\begin{array}{l}\text { Allows for optimal antiviral efficacy and } \\
\text { optimal safety profile }\end{array}$ \\
\hline
\end{tabular}

Abbreviations: CSA cyclosporine A, NPs nanoparticles, PGA polyglycerol adipate, $P L G A$ poly lactic-co-glycolic acid, $R B V$ ribavirin

cirrhosis $(n=32): 63 \%(20 / 32)$ vs. $96 \%(105 / 109)$ in noncirrhotic patients [31].

\section{Genotype 4}

In the PEARL-I phase $2 \mathrm{~b}$ randomized, open-label trial, 12 weeks of ombitasvir (25 mg) plus paritaprevir (150 mg) plus ritonavir (100 mg) combination therapy (once daily), with or without RBV, was studied in 135 non-cirrhotic patients with chronic HCV G4. SVR12 rates of $100 \%(42 / 42)$ and $91 \%(41 / 44)$ were found in naïve patients with and without RBV, respectively, with no statistically significant differences. For previously treated patients, the SVR12 rate of the triple combination with RBV was 100\% (49/49). No virological failures occurred in the RBV-containing regimen, while there was a $5 \%$ relapse and $2 \%$ virological breakthrough in naïve patients who did not receive RBV. There were some side effects such as headache, asthenia, fatigue, insomnia and anemia in some of the treatment-experienced patients on RBV [32].

The results from an open-labeled cohort, phase $2 \mathrm{a}$ trial that was conducted on HCV G4 naïve and treatment-experienced patients with or without cirrhosis who received sofosbuvir $(400 \mathrm{mg})$ and ledipasvir (90 mg) combination for 12 weeks showed 95\% (20/21) SVR12 rate. This study provided an IFN/RBV-free 


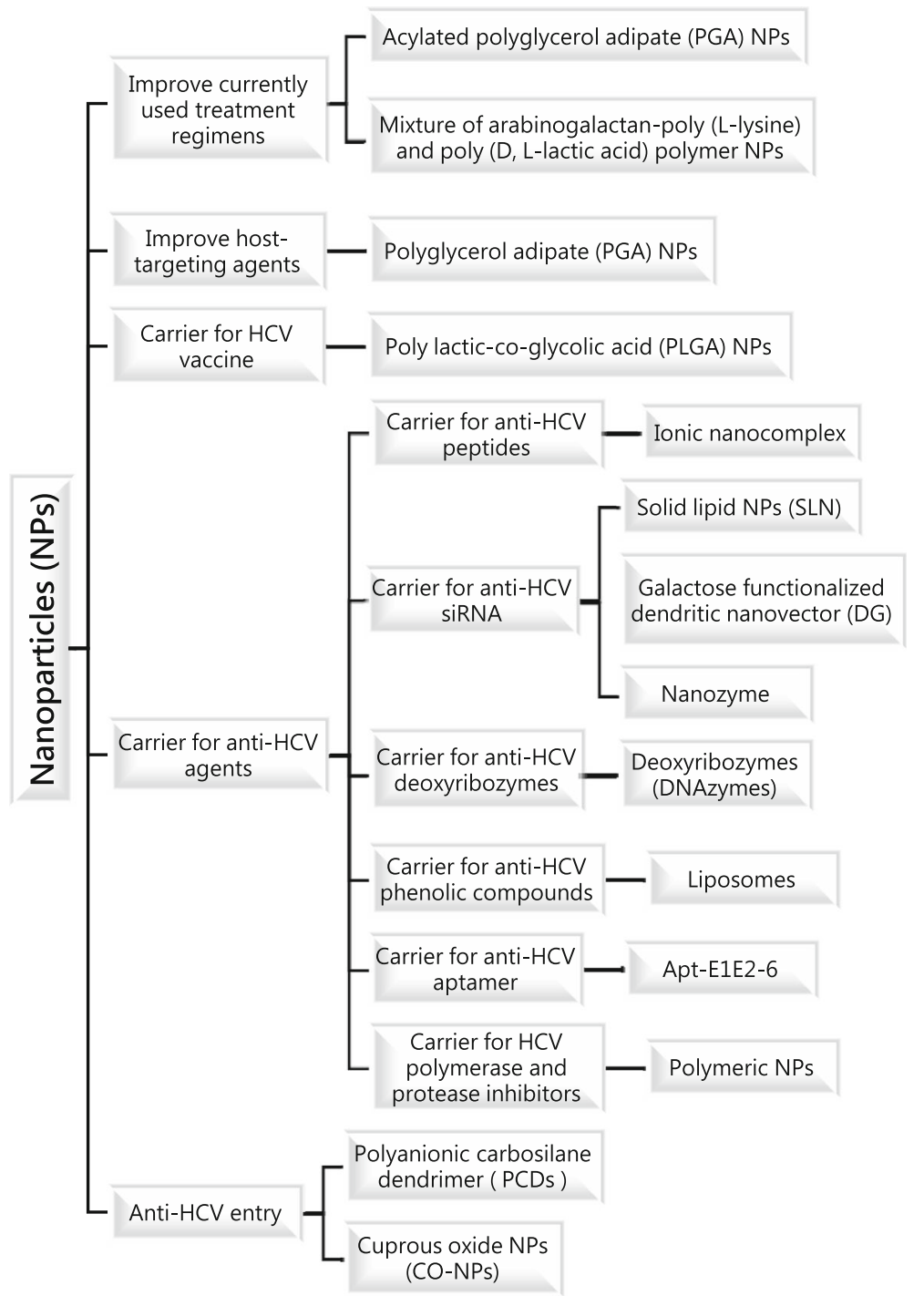

Fig. 1 A summary diagram showing how nanoparticles are used as carriers for anti-HCV agents

regimen for HCV G4 with a simple dosing of one tablet per day [33].

\section{Other genotypes}

Across the world, HCV genotypes 5 and 6 represent only $1 \%$ and $5 \%$ of genotypes, respectively, from the total prevalence of all HCV genotypes, and the therapeutic trial for these genotypes has not been clear until recently [6].

\section{Pangenotypic}

In a phase III trial (ASTRAL-1), the new DAAs regimen with velpatasvir (100 mg) and sofosbuvir (400 mg) once daily was evaluated in 624 patients across genotypes 1 to 6 in chronic HCV-infected patients, including those with compensated cirrhosis, for 12 weeks. The SVR rate was
99\% for both treatment-naïve and treatment-experienced patients, including those with compensated cirrhosis. There were some serious adverse events in $2 \%$ of the patients such as extremity necrosis, acute myocardial infarction, appendicitis, cellulitis, chronic obstructive pulmonary disease, gastroenteritis, influenza, lung cancer, small intestinal obstruction, and sudden death from unknown cause and other symptoms [34].

In the COMMAND phase II study, patients with $\mathrm{HCV}$ G2 or G3 infection were treated with $60 \mathrm{mg}$ daclatasvir plus PEG-IFN/RBV for 12 or 16 weeks compared to a PEG-IFN/RBV arm for 24 weeks. The SVR rate of 12 - or 16-week treatment in $\mathrm{HCV}$ G2-naïve patients who received daclatasvir plus PEG-IFN/RBV was $83 \%$ in both durations compared to $63 \%$ in the PEG-IFN/RBV arm. In HCV G3 groups, the SVR24 rates after 12- or 16- 


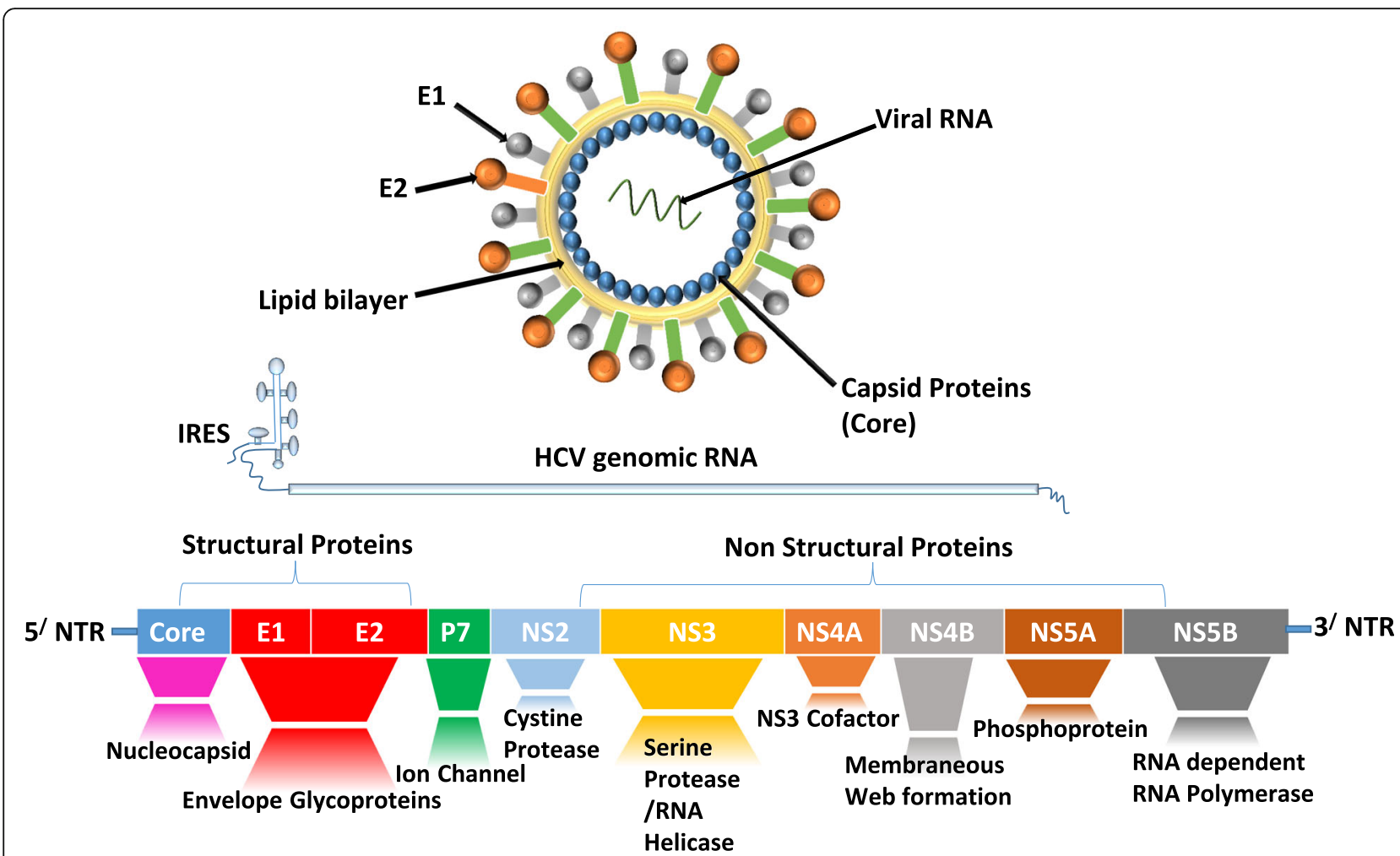

Fig. 2 The HCV genome consists of a 9.6 kilobase ORF flanked with $5^{\prime}$ and $3^{\prime}$ untranslated regions. IRES-mediated translation of the ORF produces polyprotein that is processed by cellular and viral proteases into ten viral proteins: C, E1 and E2 structural proteins, and P7, NS2, NS3, NS4A, NS4B, NS5A and NS5B non-structural proteins. Abbreviations: C: Core protein, IRES: Internal ribosome entry site, ORF: Open reading frame, NS: Non-structural protein

week treatments were $69 \%$ and $67 \%$, respectively, compared to the PEG-IFN/RBV arm (59\%), so the addition of daclatasvir to PEG-IFN/RBV is associated with higher SVR24 rate compared with PEG-IFN/RBV alone in both genotypes. Moreover, daclatasvir plus PEG-IFN/RBV treatment had a tolerability and safety profile similar to that of PEG-IFN/RBV alone [35].

In a phase 3 study named C-EDGE, a 12-week course of grazoprevir $100 \mathrm{mg}$ /elbasvir $50 \mathrm{mg}$ was used in treatment-naïve patients with genotype 1,4 or 6 among

Table 2 FDA-approved antiviral and combinations for HCV treatment in different genotypes

\begin{tabular}{|c|c|c|c|c|c|c|c|c|c|c|c|}
\hline Genotype & Drug & PEG-IFN & RBV & Boceprevir & Telaprevir & Simeprevir & Sofosbuvir & Ledipasvir & Ombitasvir & $\begin{array}{l}\text { Paritaprevir/ } \\
\text { Ritonavir }\end{array}$ & Dasabuvir \\
\hline $1,2,3,6$ & PEG-IFN & & $\bullet$ & & & & & & & & \\
\hline $1,2,3,6$ & RBV & $\bullet$ & & & & & & & & & \\
\hline 1 & Boceprevir & $\bullet$ & $\bullet$ & & & & & & & & \\
\hline 1 & Telaprevir & $\bullet$ & $\bullet$ & & & & & & & & \\
\hline 1 & Simeprevir & $\bullet$ & $\bullet$ & & & & & & & & \\
\hline 1,4 & Sofosbuvir & $\bullet$ & $\bullet$ & & & & & & & & \\
\hline 2,3 & & & $\bullet$ & & & & & & & & \\
\hline 1 & & & $\bullet$ & & & $\bullet$ & & & & & \\
\hline 1 & Ledipasvir & & & & & & $\bullet$ & & & & \\
\hline 1 & Ombitasvir & & & & & & & & & $\bullet$ & $\bullet$ \\
\hline 1 & & & $\bullet$ & & & & & & & $\bullet$ & • \\
\hline 4 & Paritaprevir/Ritonavir & & $\bullet$ & & & & & & $\bullet$ & & \\
\hline 3 & Dasabuvir & & & & & & $\bullet$ & & & & \\
\hline
\end{tabular}


421 cirrhotic and non-cirrhotic participants. Results from this study showed high SVR12 rates ranging from $80 \%$ up to $100 \%$ in treatment-naïve cirrhotic and noncirrhotic patients according to the genotype. There were no serious treatment-related adverse events [36].

A study by Esteban and colleagues gave an option for genotype 2 and 3 patients who had experienced sofosbuvir failure. The patients received $400 \mathrm{mg}$ sofosbuvir and $1000 \mathrm{mg}$ RBV weekly for 24 weeks or sofosbuvir/ PEG-IFN (180 mg)/RBV for 12 weeks. The overall SVR rates were $96 \%$ for G3 and $100 \%$ for G2 patients [37].

\section{MicroRNA as a therapeutic tool against HCV}

MicroRNAs (miRNAs) are a class of short endogenous non-coding RNAs ( 22 nucleotides) that mediate posttranscriptional regulation of gene expression [38]. They play important regulatory roles in many biological processes. miRNAs have emerged as a class of promising targets for HCV therapeutic intervention [38].

The important role of miR-122 as a host factor for $\mathrm{HCV}$ has been demonstrated. Binding of two miR-122 molecules with the $5^{\prime}$ untranslated region (UTR) of the HCV genome was found to protect the HCV 5' UTR from nucleolytic degradation and thereby promoted viral RNA stability [39]. Moreover, miR-122 binding sites are conserved in all HCV genotypes. Locked nucleic acidmodified anti-miR miravirsen was recently reported with promising antiviral activity against all HCV genotypes $[39,40]$. Miravirsen was initially assessed in an animal model for chronic $\mathrm{HCV}$ with 12 weeks of i.v. dosing [41]. The high dose treatment group $(5 \mathrm{mg} / \mathrm{kg})$ showed a marked and long-lasting decline of viral titer with no evidence of viral rebound or side effects in the treated animals. On the other hand, data from the first phase 2 study in HCV-infected patients showed a marked decline in HCV RNA levels $(\log 10 \mathrm{IU} / \mathrm{mL})$ in patients receiving $7 \mathrm{mg} / \mathrm{kg}$ [42]. Also in this study, no escape mutations were detected in the miR-122 binding sites, indicating the low incidence of miravirsen resistance.

\section{Potential of nanotechnology to improve currently used treatment regimens}

Ribavirin is an effective nucleoside analogue used in the treatment of chronic $\mathrm{HCV}$ along with IFN. However, it has a restricted clinical application because it induces dose-dependent hemolytic anemia as a result of its accumulation inside red blood cells [43]. Many studies have reported the use of nanotechnology to try and solve this problem. For example, red blood cells have no endocytic mechanism [44] and low uptake of nanoparticles [45]. Polyglycerol adipate (PGA) and acylated PGA nanoparticles have been used as a carrier for RBV boronic acid, instead of using RBV only, because this provides RBV with hydrophobicity and increases the nanoparticles' drug loading efficiency [46].

Ishihara et al. encapsulated RBV monophosphate in biodegradable nanoparticles prepared from a mixture of arabinogalactan-poly (L-lysine) and poly (D, L-lactic acid) polymer. The novel, stable, biodegradable nanocomplex showed a dual function of targeting hepatocytes and sustained release of RBV (37 days in PBS and 7 days after intravenous injection in mice). This nanoformulation is expected to display high antiviral activity and decrease the side effects of RBV [47].

\section{Potential of nanotechnology to improve host-targeting agents}

Jyothi et al. used poly lactic-co-glycolic acid (PLGA) nanoparticles conjugated with liver targeting peptide (CKNEKKNKIERNNKLKQPP) to encapsulate cyclosporine A, an HCV inhibitor, via targeting the host factor cyclophilin A. These nanoparticles displayed high specificity to the liver cells, reduced the toxic and immunosuppressive effects of free cyclosporine A, and significantly inhibited HCV replication in a mouse model [48]. All of the above make this nanoformulation promising as a safe and efficient delivery system for HCV treatment.

\section{Nanoparticles as carrier for HCV vaccine}

Jiao et al. utilized the ability of CpG oligodeoxynucleotide as an adjuvant and immunomodulatory together with recombinant HCV NS3 as an HCV vaccine model by encapsulating them in a cationic liposome. They found that this model increased not only cellular but also humoral immune response against HCV NS3. It dramatically induced a Th1 immune response against HCV [49].

In an animal study, mice were immunized with $10 \mathrm{mg}$ recombinant $\mathrm{HCV} \mathrm{NS3}$ proteins with or without $50 \mathrm{mg}$ $\mathrm{CpG}$ or $\mathrm{GpC}$, either in free form or encapsulated in cationic liposomes. Samples were collected weekly for up to 8 weeks after immunization. Mice immunized with either liposome-NS3-CpG or liposome-NS3 produced 1:4-fold more cells secreting IFN- $\gamma$ than secreted IL-4. The cells secreting IFN- $\gamma$ in mice immunized with freeNS3 were only one-sixteenth of the cells secreting IL-4, indicating that liposomes encapsulating NS3 alone or with CpG have the ability to switch the immune response against HCV NS3 from the Th2 to the Th1 pathway [49].

\section{Nanoparticles as carrier for anti-HCV peptides}

$\mathrm{P} 41$, an amphipathic alpha-helical cationic peptide derived from $\mathrm{HCV}$ NS5A membrane anchor domain C5A, was observed to have antiviral activity against HCV [50] and HIV [51], but rapid removal from circulation and toxicity of the cationic peptide restricted its use. So, Zhang et al. incorporated it into an ionic nanocopmlex 
that highly decreased cytotoxicity, hemolytic effect and proteolytic degradation while maintaining its antiviral activity against $\mathrm{HIV}$ and $\mathrm{HCV}$ [52].

Zhang et al. formulated an antiviral peptide nanocomplex using P41 electrostatically coupled with anionic poly (amino acid) based block copolymer with galactose as an active targeting moiety. This study revealed that galactosylated antiviral peptide nanocomplexes offered asialoglycoprotein receptor mediated uptake in hepatoma cell lines and robust inhibition of the $\mathrm{HCV}$ core and NS5A proteins from binding with lipid droplets, which is known to be an essential step for viral assembly and release [53].

\section{Nanoparticles as carrier for anti-HCV siRNA}

RNA interference (RNAi) is a short interfering 21-23 nucleotides double-stranded RNA segment that can knockdown gene expression through managing mRNA degradation in a sequence-specific manner, and its mechanism depends on post-transcriptional gene silencing [54]. RNAi can precisely inhibit HCV RNA replication and protein expression in Huh-7 cells infected with $\mathrm{HCV}$ genome, and the antiviral effect is independent of IFN [55]. siRNA encounters some problems including low cellular uptake, rapid degradation by nucleases as well as inadequate blood stability [56], so many studies have used nanoparticles to solve these problems and to minimize the adverse effect of "off-targeting". Lakshminarayanan et al. used a galactose functionalized dendritic nanovector (DG) as a carrier for siRNA against the $5^{\prime}$ untranslated region of the HCV genome [18]. The siRNA-DG formed a stable complex that had target-oriented delivery through the interaction between its free galactose residues and asialoglycoprotein receptor. The delivered siRNA localized in the perinuclear region (the site of HCV replication) in which NS3 and NS5b viral proteins are co-localized. There was a significant inhibition in JFH1 RNA titer, so this new siRNA-DG nanovector is a promising option for HCV therapeutics [18].

Torrecilla et al. used an RNA interference strategy to inhibit the IRES by using shRNA74 short hairpin plasmid decorated on solid lipid nanoparticles (SLN) with hyaluronic acid (HA) or dextran (DX) as a non-viral vector. The SLN-HA and SLN-DX nanoparticles were shown to protect shRNA74 from DNase activity and rapid cell trafficking. The silencing efficiency of SLN-HA was more than SLN-DX [57].

Hang et al. found that cuprous oxide nanoparticles (CO-NP) at concentration of $2 \mu \mathrm{g} / \mathrm{ml}$ significantly inhibited the $\mathrm{HCVcc} / \mathrm{Huh7} 7.5 .1$ cell line and also inhibited the HCVpp entry by more than $70 \%$. This study revealed that $\mathrm{CO}-\mathrm{NPs}$ blocked $\mathrm{HCV}$ attachment and entry. They hypothesized that CO-NP probably interacts with the surface of virion that in turn blocks the receptor binding sites present on the HCV envelope and thus prevent viral attachment [58].

\section{Nanoparticles as carrier for anti-HCV deoxyribozymes}

Deoxyribozymes (DNAzymes) are RNA cleaving, short DNA molecules that can cleave a short target RNA substrate in a sequence-specific way [59]. They are tremendously efficient under simulated physiological environments, less expensive than siRNA, and can be easily chemically modified and with higher stability than RNA in serum [60]. Iron oxide magnetic nanoparticles (MNs) were used as a carrier for DNAzyme Dz681 selected for HCV NS3 RNA targeting in addition to cell penetrating peptide (MPAP) as an anti-HCV nanoformulation. DzMPAP-MN inhibited HCV NS3 replication in a Huh-7 Luc-Neo cell line through the knockdown of HCV NS3 gene expression. Moreover, it had a higher knockdown efficiency than the free DNAzyme transfected with Lipofectamine 2000 and did not induce any undesired immune responses in Huh-7 cells. Thus it has potential as a novel tool in clinical treatment of $\mathrm{HCV}[61,62]$.

\section{Nanoparticles as carrier for anti-HCV phenolic compounds}

Silibinin, the active polyphenolic agent of milk thistle, has been indicated to inhibit HCV virus entry and replication $[63,64]$, but it has poor water solubility and bioavailability. Ripoli et al. used liposomes as a nanovector to solubilize and deliver silibinin. The designed nanoparticles were found to be non-toxic and had high antiviral activity to prevent entry with preferential absorption by hepatocytes [65].

\section{Nanoparticles as carrier for anti-HCV aptamer}

Aptamers are single-stranded oligonucleotide sequences, RNA or DNA, and can bind with high affinity and specificity to a wide range of targets such as peptides, proteins, drugs, and whole cells and viruses depending on their specific binding pockets for the target molecule. Nanomaterial-based aptamer bioconjugates have generated substantial interest and a wide variety of applications in medicine [66]. In an attempt to mechanically decrease the HCV load in plasma, Delaviz et al. designed a specific magnetic nanoconjugate for $\mathrm{HCV}$ treatment using an aptamer (Apt-E1E2-6) with a high affinity for HCV E1 E2 glycoproteins. The aptamer-conjugated magnetic nanoparticles efficiently eradicated HCV particles and decreased the viral titer from human plasma samples, providing a non-invasive technique for $\mathrm{HCV}$ removal with minimal side effects [67]. 


\section{Nanoparticles as carrier for HCV polymerase and protease inhibitors}

A novel nanoformulation is a combination of HCV protease and polymerase inhibitors along with anti-fibrotic/ anti-hemolytic and viral entry inhibitor agents using a combination of naturally driven polyphenol/thiols and non-anticoagulant GAGs [68]. These compounds are effective antiviral agents, especially in inhibiting the function of the various genotypes of HCV. Another polymeric nanoparticle-based technology platform incorporated the PI RBV or taribavirin and various types of polymerase inhibitors in the treatment of hepatitis $\mathrm{C}$, along with anti-fibrotic/anti-hemolytic viral entry inhibitor $[68,69]$. Furthermore, a conjugation with a therapeutic peptide, p14 (NS3 peptide) that confers the ability to target viral NS3 helicase is anticipated to increase the efficacy of the drugs encapsulated into the nanoparticle platform [69]. Drug-loaded nanoparticles were attached to monoclonal antibody fragments directed against epitopes conserved on the HCV surface E2 glycoprotein of genotypes $1 \mathrm{a}, 1 \mathrm{~b}, 2 \mathrm{a}, 2 \mathrm{~b}$ and 4 for targeted delivery of antiviral drugs [69]. Thus, the nano-incorporation of PIs and polymerase inhibitors along with anti-fibrotic/antihemolytic and viral entry inhibitors allow for optimal antiviral efficacy and optimal safety profiles [68, 69].

\section{Nanoparticles alone as an anti-HCV}

Sepúlveda-Crespo et al. have identified a family of polyanionic carbosilane dendrimers that can inhibit HCV infection in tissue culture. The most effective of these compounds was G2-S24P (EC50 $=3 \pm 1 \mathrm{nM})$. It inhibited HCV infection more than $80 \%$ by interfering with extracellular virions at the early steps of viral entry. It also displayed an additive effect in combination with sofosbuvir [70].

\section{Conclusions}

In recent years many diverse scientific strategies have been developed for HCV therapy. Therapeutic options for $\mathrm{HCV}$ infection have been limited by drug resistance and adverse side effects. Targeting of the HCV replication was a promising strategy for antiviral therapy. However, due to its immunosuppressive activity and severe side effects, clinical applications in this category have been limited. To overcome these obstacles, researchers now have successfully developed drug delivery systems by conjugating the different antiviral drugs to different models of nanoparticles. Also, nanoparticles provide an alternate method for antigen delivery, which not only activates different elements of the immune system but also has good biocompatibility. One of the ways in which nanoparticles are able to elicit different immune responses is through their size; they move into cells via non-classical pathways and then are processed as such. One of the most widely used delivery systems is lipid nanoparticles. They are characterized by simplicity of production and safety, which encourages their use for in vivo application of RNAi. Moreover, lipid nanoparticles may be functionalized to reach target cells, and they may be used to combine RNAi molecules with conventional drug substances to reduce resistance or improve efficiency.

One of the unique advantages of nanotechnology in addition to the efficiency of drug delivery to pathological areas is its ability to decrease drugs' toxicity and side effects. We herein discussed that a nanoparticle delivery system can be safe and may be a Trojan horse for future therapies against $\mathrm{HCV}$.

\section{Abbreviations \\ DAA: Direct-acting antivirals; HCV: Hepatitis C virus; HTA: Host targeting antiviral; IRES: Internal ribosome entry site; PEG-IFN: Pegylated interferon; PI: Protease inhibitor; RBV: Ribavirin; SVR12: Sustained virological response for 12 consecutive weeks; SVR24: Sustained virological response for 24 consecutive weeks}

\section{Acknowledgements}

Not applicable.

\section{Funding}

We are grateful for the generous donation of Science and Technology Development Funds (STDF) for granting a short term fellowship (STF 12308) to ME for work at PRI, Albany College of Pharmacy and Health Science, Albany, NY, USA.

Availability of data and materials Not applicable.

\section{Authors' contributions}

MHE and NHED performed literature searches and drafted the manuscript. SAM wrote sections of the manuscript and edited all version. All authors read and approved the final manuscript.

\section{Competing interests}

SA Mousa has HCV-related patent applications as referenced in this manuscript as references $[68,69]$. For all other authors there are no competing interests.

Consent for publication

Not applicable.

Ethics approval and consent to participate

Not applicable.

\section{Publisher's Note}

Springer Nature remains neutral with regard to jurisdictional claims in published maps and institutional affiliations.

\section{Author details \\ ${ }^{1}$ The Pharmaceutical Research Institute, Albany College of Pharmacy and Health Sciences, Rensselaer, NY 12144, USA. ${ }^{2}$ National Cancer Institute, Cairo University, Cairo, Egypt. ${ }^{3}$ Faculty of Medicine, Mansoura University, Mansoura, Egypt.}

Received: 16 February 2017 Accepted: 19 April 2017

Published online: 02 May 2017

\section{References}

1. Shepard CW, Finelli L, Alter MJ. Global epidemiology of hepatitis C virus infection. Lancet Infect Dis. 2005;5:558-67.

2. Lauer GM, Walker BD. Hepatitis C virus infection. N Engl J Med. 2001;345:41-52.

3. Schaefer EA, Chung RT. Anti-hepatitis $C$ virus drugs in development. Gastroenterology. 2012;142:1340-50. e1. 
4. Zein NN, Persing DH. Hepatitis C genotypes: current trends and future implications. Mayo Clin Proc. 1996;71:458-62.

5. Bartenschlager R, Lohmann V. Replication of hepatitis C virus. J Gen Virol. 2000;81:1631-48.

6. Messina JP, Humphreys I, Flaxman A, Brown A, Cooke GS, Pybus OG, et al. Global distribution and prevalence of hepatitis $C$ virus genotypes. Hepatology. 2015;61:77-87.

7. Alter MJ. Epidemiology of hepatitis C. Hepatology. 1997;26:62S-5S.

8. Alter MJ. Prevention of spread of hepatitis C. Hepatology. 2002;36:S93-8.

9. McEwan P, Ward T, Webster S, Kalsekar A, Brenner M, Yuan Y. Modeling the cost-effectiveness of the all oral, direct-acting antiviral regimen daclatasvir plus sofosbuvir in patients co-infected with hepatitis $\mathrm{C}$ virus (HCV) and HIV. Value Health. 2015;18:A628.

10. Pawlotsky JM. Therapy: avoiding treatment failures associated with HCV resistance. Nat Rev Gastroenterol Hepatol. 2015;12:673-4.

11. Kwong AD, Kauffman RS, Hurter P, Mueller P. Discovery and development of telaprevir: an NS3-4A protease inhibitor for treating genotype 1 chronic hepatitis C virus. Nat Biotechnol. 2011;29:993-1003.

12. Welsch C, Jesudian A, Zeuzem S, Jacobson I. New direct-acting antiviral agents for the treatment of hepatitis C virus infection and perspectives. Gut. 2012;61 Suppl 1:i36-46.

13. Fonseca-Coronado S, Escobar-Gutierrez A, Ruiz-Tovar K, Cruz-Rivera MY, Rivera-Osorio P, Vazquez-Pichardo M, et al. Specific detection of naturally occurring hepatitis $C$ virus mutants with resistance to telaprevir and boceprevir (protease inhibitors) among treatment-naive infected individuals. J Clin Microbiol. 2012;50:281-7.

14. Aman W, Mousa S, Shiha G, Mousa SA. Current status and future directions in the management of chronic hepatitis C. Virol J. 2012;9:57.

15. Belousova $\vee$, Abd-Rabou AA, Mousa SA. Recent advances and future directions in the management of hepatitis $C$ infections. Pharmacol Ther. 2015;145:92-102

16. Singh S. Nanomedicine-nanoscale drugs and delivery systems. J Nanosci Nanotechnol. 2010;10:7906-18.

17. Sosnik A, Amiji M. Nanotechnology solutions for infectious diseases in developing nations. Preface Adv Drug Deliv Rev. 2010;62:375-7.

18. Lakshminarayanan A, Reddy BU, Raghav N, Ravi VK, Kumar A, Maiti PK, et al. A galactose-functionalized dendritic siRNA-nanovector to potentiate hepatitis C inhibition in liver cells. Nanoscale. 2015;7:16921-31.

19. Bartenschlager R, Sparacio S. Hepatitis C virus molecular clones and their replication capacity in vivo and in cell culture. Virus Res. 2007;127:195-207.

20. Tsukiyama-Kohara K, lizuka N, Kohara M, Nomoto A. Internal ribosome entry site within hepatitis C virus RNA. J Virol. 1992;66:1476-83.

21. Hijikata M, Mizushima H, Akagi T, Mori S, Kakiuchi N, Kato N, et al. Two distinct proteinase activities required for the processing of a putative nonstructural precursor protein of hepatitis C virus. J Virol. 1993;67:4665-75.

22. Grakoui A, McCourt DW, Wychowski C, Feinstone SM, Rice CM. A second hepatitis C virus-encoded proteinase. Proc Natl Acad Sci U S A. 1993;90:10583-7.

23. Bartenschlager $\mathrm{R}$, Ahlborn-Laake L, Mous J, Jacobsen H. Nonstructural protein 3 of the hepatitis $C$ virus encodes a serine-type proteinase required for cleavage at the NS3/4 and NS4/5 junctions. J Virol. 1993;67:3835-44.

24. Pallaoro M, Lahm A, Biasiol G, Brunetti M, Nardella C, Orsatti L, et al. Characterization of the hepatitis C virus NS2/3 processing reaction by using a purified precursor protein. J Virol. 2001;75:9939-46.

25. Han SH, Kim SJ, Kim EJ, Kim TE, Moon JS, Kim GW, et al. Phosphorylation of hepatitis C virus RNA polymerases ser29 and ser42 by protein kinase Crelated kinase 2 regulates viral RNA replication. J Virol. 2014;88:11240-52.

26. Zeuzem S, Hezode C, Bronowicki JP, Loustaud-Ratti V, Gea F, Buti M, et al. Daclatasvir plus simeprevir with or without ribavirin for the treatment of chronic hepatitis C virus genotype 1 infection. J Hepatol. 2016;64:292-300.

27. Morelli G, Firpi R, Horne P, Peter J, Askushevich L, Vainorius M, et al. Openlabel study to evaluate the safety \& tolerability of telaprevir in combination with sofosbuvir in naive subjects with HCV genotype 1. J Gastroenterol Hepatol Res. 2015:4:1599-604.

28. Kwo P, Gitlin N, Nahass R, Bernstein D, Rojter S, Schiff E, et al. A phase-3, randomised, open-label study to evaluate the efficacy and safety of 8 and 12 weeks of simeprevir (SMV) plus sofosbuvir (SOF) in treatment-naive andexperienced patients with chronic HCV genotype 1 infection without cirrhosis: Optimist-1. J Hepatol. 2015;62:S270.

29. Stedman CA, Hyland RH, Ding X, Pang PS, McHutchison JG, Gane EJ. Once daily ledipasvir/sofosbuvir fixed-dose combination with ribavirin in patients with inherited bleeding disorders and hepatitis C genotype 1 infection. Haemophilia. 2015. doi 10.1111/hae.12791

30. Bourliere M, Adhoute X, Ansaldi C, Oules V, Benali S, Portal I, et al. Sofosbuvir plus ledipasvir in combination for the treatment of hepatitis $C$ infection. Expert Rev Gastroenterol Hepatol. 2015;9:1483-94.

31. Nelson DR, Cooper JN, Lalezari JP, Lawitz E, Pockros PJ, Gitlin N, et al. Alloral 12-week treatment with daclatasvir plus sofosbuvir in patients with hepatitis C virus genotype 3 infection: ALLY-3 phase III study. Hepatology. 2015;61:1127-35.

32. Hezode C, Asselah T, Reddy KR, Hassanein T, Berenguer M, FleischerStepniewska K, et al. Ombitasvir plus paritaprevir plus ritonavir with or without ribavirin in treatment-naive and treatment-experienced patients with genotype 4 chronic hepatitis C virus infection (PEARL-I): a randomised, open-label trial. Lancet. 2015;385:2502-9.

33. Kohli A, Kapoor R, Sims Z, Nelson A, Sidharthan S, Lam B, et al. Ledipasvir and sofosbuvir for hepatitis $C$ genotype 4: a proof-ofconcept, single-centre, open-label phase 2a cohort study. Lancet Infect Dis. 2015;15:1049-54.

34. Feld JJ, Jacobson IM, Hezode C, Asselah T, Ruane PJ, Gruener N, et al. Sofosbuvir and velpatasvir for HCV genotype 1, 2, 4, 5, and 6 infection. N Engl J Med. 2015;373:2599-607.

35. Dore GJ, Lawitz E, Hezode C, Shafran SD, Ramji A, Tatum HA, et al. Daclatasvir plus peginterferon and ribavirin is noninferior to peginterferon and ribavirin alone, and reduces the duration of treatment for $\mathrm{HCV}$ genotype 2 or 3 infection. Gastroenterology. 2015;148:355-66. e1.

36. Zeuzem S, Ghalib R, Reddy KR, Pockros PJ, Ben Ari Z, Zhao Y, et al. Grazoprevir-elbasvir combination therapy for treatment-naive cirrhotic and noncirrhotic patients with chronic hepatitis C virus genotype 1, 4, or 6 infection: A randomized trial. Ann Intern Med. 2015;163:1-13.

37. Esteban R, Nyberg L, Lalezari J, Ni L, Doehle B, Kanwar B, et al. Successful retreatment with sofosbuvir-containing regimens for HCV genotype 2 or 3 infected patients who failed prior sofosbuvir plus ribavarin therapy. J Hepatology. 2014;1:S4-5.

38. van Rooij $\mathrm{E}$, Kauppinen S. Development of microRNA therapeutics is coming of age. EMBO Mol Med. 2014;6:851-64.

39. Mortimer SA, Doudna JA. Unconventional miR-122 binding stabilizes the HCV genome by forming a trimolecular RNA structure. Nucleic Acids Research. 2013:41:4230-40.

40. Shimakami T, Yamane D, Jangra RK, Kempf BJ, Spaniel C, Barton DJ, et al. Stabilization of hepatitis C virus RNA by an Ago2-miR-122 complex. Proc Natl Acad Sci USA. 2012;109:941-6.

41. Lanford RE, Hildebrandt-Eriksen ES, Petri A, Persson R, Lindow M, Munk ME, et al. Therapeutic Silencing of MicroRNA-122 in primates with chronic Hepatitis C virus infection. Science. 2010;327:198-201.

42. Janssen HL, Reesink HW, Lawitz EJ, Zeuzem S, Rodriguez-Torres M, Patel K, et al. Treatment of HCV infection by targeting microRNA. N Engl J Med. 2013:368:1685-94

43. Bodenheimer Jr HC, Lindsay KL, Davis GL, Lewis JH, Thung SN, Seeff LB. Tolerance and efficacy of oral ribavirin treatment of chronic hepatitis C: a multicenter trial. Hepatology. 1997;26:473-7.

44. Schekman R, Singer SJ. Clustering and endocytosis of membrane receptors can be induced in mature erythrocytes of neonatal but not adult humans. Proc Natl Acad Sci USA. 1976:73:4075-9.

45. Rothen-Rutishauser BM, Schurch S, Haenni B, Kapp N, Gehr P. Interaction of fine particles and nanoparticles with red blood cells visualized with advanced microscopic techniques. Environ Sci Technol. 2006;40:4353-9.

46. Abo-zeid Y, Irving W, Thomson B, Mantovani G, Garnett M. P19: Ribavirinboronic acid loaded nanoparticles: a possible route to improve hepatitis $C$ treatment. J Viral Hepatitis. 2013:20:26-7.

47. Ishihara T, Kaneko K, Ishihara T, Mizushima T. Development of biodegradable nanoparticles for liver-specific ribavirin delivery. J Pharm Sci. 2014:103:4005-11.

48. Jyothi KR, Beloor J, Jo A, Nguyen MN, Choi TG, Kim JH, et al. Liver-targeted cyclosporine A-encapsulated poly (lactic-co-glycolic) acid nanoparticles inhibit hepatitis C virus replication. Int J Nanomedicine. 2015;10:903-21.

49. Jiao X, Wang RY, Qiu Q, Alter HJ, Shih JW. Enhanced hepatitis C virus NS3 specific Th1 immune responses induced by co-delivery of protein antigen and CpG with cationic liposomes. J Gen Virol. 2004;85:1545-53.

50. Bobardt MD, Cheng G, de Witte L, Selvarajah S, Chatterji U, Sanders-Beer BE, et al. Hepatitis C virus NS5A anchor peptide disrupts human immunodeficiency virus. Proc Natl Acad Sci U S A. 2008;105:5525-30. 
51. Cheng G, Montero A, Gastaminza P, Whitten-Bauer C, Wieland SF, Isogawa $M$, et al. A virocidal amphipathic a-helical peptide that inhibits hepatitis C virus infection in vitro. Proc Natl Acad Sci U S A. 2008;105:3088-93.

52. Zhang J, Mulvenon A, Makarov E, Wagoner J, Knibbe J, Kim JO, et al. Antiviral peptide nanocomplexes as a potential therapeutic modality for HIV/HCV co-infection. Biomaterials. 2013;34:3846-57.

53. Zhang J, Garrison JC, Poluektova LY, Bronich TK, Osna NA. Liver-targeted antiviral peptide nanocomplexes as potential anti-HCV therapeutics. Biomaterials. 2015;70:37-47.

54. Agrawal N, Dasaradhi PV, Mohmmed A, Malhotra P, Bhatnagar RK, Mukherjee SK. RNA interference: biology, mechanism, and applications. Microbiol Mol Biol Rev. 2003;67:657-85.

55. Kapadia SB, Brideau-Andersen A, Chisari FV. Interference of hepatitis C virus RNA replication by short interfering RNAs. Proc Natl Acad Sci U S A. 2003; 100:2014-8.

56. Katas H, Alpar HO. Development and characterisation of chitosan nanoparticles for siRNA delivery. J Control Release. 2006;115:216-25.

57. Torrecilla J, del Pozo-Rodriguez A, Apaolaza PS, Solinis MA, RodriguezGascon A. Solid lipid nanoparticles as non-viral vector for the treatment of chronic hepatitis C by RNA interference. Int J Pharm. 2015;479:181-8.

58. Hang X, Peng H, Song H, Qi Z, Miao X, Xu W. Antiviral activity of cuprous oxide nanoparticles against hepatitis C virus in vitro. J Virol Methods. 2015; 222:150-7.

59. Santoro SW, Joyce GF. A general purpose RNA-cleaving DNA enzyme. Proc Natl Acad Sci U S A. 1997;94:4262-6.

60. Appaiahgari MB, Vrati S. DNAzyme-mediated inhibition of Japanese encephalitis virus replication in mouse brain. Mol Ther. 2007;15:1593-9.

61. Ryoo SR, Jang H, Kim KS, Lee B, Kim KB, Kim YK, et al. Functional delivery of DNAzyme with iron oxide nanoparticles for hepatitis $C$ virus gene knockdown. Biomaterials. 2012;33:2754-61.

62. Min D-H, Kim D-E. Suppression of hepatitis $C$ viral genome replication with RNA-cleaving deoxyribozyme. In: Erdmann VA, Barciszewski J, editors. From nucleic acids sequences to molecular medicine. Heidelburg: Springer; 2012. p. 429-52.

63. Ahmed-Belkacem A, Ahnou N, Barbotte L, Wychowski C, Pallier C, Brillet R, et al. Silibinin and related compounds are direct inhibitors of hepatitis $C$ virus RNA-dependent RNA polymerase. Gastroenterology. 2010;138:1112-22.

64. Wagoner J, Negash A, Kane OJ, Martinez LE, Nahmias Y, Bourne N, et al. Multiple effects of silymarin on the hepatitis C virus lifecycle. Hepatology. 2010;51:1912-21.

65. Ripoli M, Angelico R, Sacco P, Ceglie A, Mangia A. Phytoliposome-based silibinin delivery system as a promising strategy to prevent hepatitis $C$ virus infection. J Biomedical Nanotech. 2016;12:770-80.

66. Tuerk C, Gold L. Systematic evolution of ligands by exponential enrichment: RNA ligands to bacteriophage T4 DNA polymerase. Science. 1990;249:505-10.

67. Delaviz N, Gill P, Ajami A, Aarabi M. Aptamer-conjugated magnetic nanoparticles for the efficient removal of HCV particles from human plasma samples. RSC Advances. 2015;5:79433-9.

68. Mousa SA. Nano-targeted delivery of protease, polymerase inhibitors with or without immune modulators in the treatment of hepatitis C. US Patent 9,597,351; 2017.

69. Mousa SA. Composition and method of use for combinations of anti-viral protease, polymerase inhibitors and natural bioactive compounds in the treatment of hepatitis C infection. 2016. US Patent application 20160346308.

70. Sepulveda-Crespo D, Jimenez JL, Gomez R, De La Mata FJ, Majano PL, Munoz-Fernandez MA, et al. Polyanionic carbosilane dendrimers prevent hepatitis C virus infection in cell culture. Nanomedicine. 2017:13:49-58.

\section{Submit your next manuscript to BioMed Central and we will help you at every step:}

- We accept pre-submission inquiries

- Our selector tool helps you to find the most relevant journal

- We provide round the clock customer support

- Convenient online submission

- Thorough peer review

- Inclusion in PubMed and all major indexing services

- Maximum visibility for your research

Submit your manuscript at www.biomedcentral.com/submit
Biomed Central 